\title{
DESENVOLVIMENTO DE PLANTAS DE CRISÂNTEMO CULTIVADAS EM VASO EM RESPOSTA A NÍVEIS DE CONDUTIVIDADE ELÉTRICA ${ }^{1}$
}

\author{
POLIANA R. D'ALMEIDA MOTA ${ }^{2}$, ROBERTO L. V. BÔAS ${ }^{3}$, \\ VALDEMÍCIO F. DE SOUSA ${ }^{4}$, VALDENIR Q. RIBEIRO ${ }^{4}$
}

\begin{abstract}
RESUMO: Na floricultura, a competição por mercados é intensa e o diferencial de produtividade consiste no manejo nutricional adequado, por promover grande impacto sobre a qualidade, a produtividade e a longevidade das inflorescências e da planta. $\mathrm{O}$ presente trabalho teve o objetivo de avaliar os efeitos de níveis de condutividade elétrica (CE) no desenvolvimento de plantas de crisântemo (Dendranthema grandiflora Tzvelev.) em vaso sob cultivo protegido. O experimento foi conduzido no município de Paranapanema - SP. Usou-se o delineamento experimental de blocos casualizados com quatro repetições e parcelas divididas. As parcelas foram constituídas pelas épocas de amostragem, e as subparcelas, pelos diferentes níveis de CE, determinados na solução aplicada via água de irrigação: 1,$42 ; 1,65 ; 1,89 ; 2,13$ e $2,36 \mathrm{dS} \mathrm{m}^{-1}$ (fase vegetativa); 1,71; 1,$97 ; 2,28 ; 2,57$ e $2,85 \mathrm{dS} \mathrm{m}^{-1}$ (fase de botão). Determinaram-se, semanalmente, a altura da planta e o diâmetro do buquê, e a cada 14 dias, a área foliar e a fitomassa seca da parte aérea da planta. $\mathrm{O}$ tratamento, correspondente à aplicação de solução com CE de $2,13 \mathrm{dS} \mathrm{m}^{-1}$ na fase vegetativa e $2,57 \mathrm{dS} \mathrm{m}^{-1}$ na fase de botão, proporcionou melhor aspecto visual das plantas, além de apresentar maior valor de fitomassa seca da parte aérea, maior área foliar e melhores formação e coloração.
\end{abstract}

PALAVRAS-CHAVE: Dendranthema grandiflora, fertirrigação, ambiente protegido.

\section{DEVELOPMENT OF CHRYSANTHEMUM PLANTS CULTIVATED IN FLOWERPOT IN RESPONSE TO ELECTRICAL CONDUCTIVITY LEVELS}

\begin{abstract}
In floriculture market, the competition is intense and the productivity differential consists in an appropriated nutritional management which provides a large impact in quality, productivity and longevity of the flowers and plants. This present work aimed to evaluate the effects of electrical conductivity (EC) levels in chrysanthemum plant (Dendranthema grandiflora Tzvelev.) development. These plants were planted in pots and cultivated in a greenhouse. The experiment was carried out in Paranapanema city, São Paulo State. The experimental design was made in randomized blocks with four repetitions and split plots. The plots were constituted according to the sample times, and the split plots according to the different EC levels which were determined in the applied water irrigation solution: $1.42 ; 1.65 ; 1.89 ; 2.13$ and $2.36 \mathrm{dS} \mathrm{m}^{-1}$ (vegetative stage); $1.71 ; 1.97 ; 2.28 ; 2.57$ and $2.85 \mathrm{dS} \mathrm{m}^{-1}$ (bud stage). The plant height and the bouquet diameter were weekly evaluated, and every 14 days the leaf area and the dry mass of the aerial portion of the plant were measured. The treatment which applied the EC level of $2.13 \mathrm{dS} \mathrm{m}^{-1}$ during the vegetative stage and $2.57 \mathrm{dS} \mathrm{m}^{-1}$ during the bud stage provided the best visual aspect in plants, as well as the higher aerial part if the dry mass, higher leaf area and the best formation and coloring.
\end{abstract}

KEYWORDS: Dendranthema grandiflora, fertigation, greenhouse.

\footnotetext{
${ }^{1}$ Extraído da Dissertação de Mestrado do primeiro autor.

${ }^{2}$ Eng $^{\mathrm{a}}$ Agrônoma, Doutoranda em Irrigação e Drenagem, Departamento de Recursos Naturais/Ciência do Solo, Faculdade de Ciências Agronômicas, UNESP, Botucatu - SP, Fone/Fax: (OXX14) 3811.7266- R: 230, polimota@ @ca.unesp.br

${ }^{3}$ Eng ${ }^{\mathrm{o}}$ Agrônomo, Prof. Doutor, Departamento de Recursos Naturais/Ciência do Solo, UNESP, Botucatu - SP. Bolsista de Produtividade CNPq.

${ }^{4}$ Engo ${ }^{\circ}$ Agrônomo, Pesquisador da Embrapa Meio-Norte, Teresina - PI.

Recebido pelo Conselho Editorial em: 7-6-2005
}

Aprovado pelo Conselho Editorial em: 19-1-2007 


\section{INTRODUÇÃO}

O mercado mundial de flores e plantas ornamentais está em plena expansão e tem como principal exportador a Holanda, seguida pela Colômbia e Itália, entre outros. O Brasil tem ainda participação pouco expressiva no segmento mundial, no entanto vem expandindo sua produção ao longo dos anos.

A produção nacional de flores movimenta 500 milhões de reais por ano, em nível de produtor, e US\$ 15 milhões em exportação. Estima-se que cerca de 7.600 produtores em 1.500 municípios brasileiros se dedicam à floricultura em tempo integral ou parcial, numa área cultivada de 9.000 ha, empregando cerca 33,3 mil trabalhadores rurais diretos (KIYUNA et al., 2004).

Dentre as plantas mais vendidas nos três maiores mercados nacionais, o crisântemo em vaso encontra-se em posição de destaque: terceiro lugar na CEASA de Campinas, quinto no Veiling de Holambra e sétimo na CEAGESP de São Paulo (JUNQUEIRA \& PEETZ, 2004).

$\mathrm{Na}$ floricultura, cuja competição por mercados é intensa, o diferencial de produtividade consiste no manejo adequado de fatores ambientais para uma produção satisfatória, mas a grande dificuldade é que a expansão da cultura ainda enfrenta os limites da falta de informações sobre o seu cultivo. Uma dessas é o conhecimento das necessidades nutricionais da cultura, a qual está intrinsecamente relacionada à adubação que, juntamente com a nutrição, promovem grande impacto sobre a qualidade, a produtividade e a longevidade das inflorescências e da planta. A nutrição e a adubação também possuem importância ecológica, pois a utilização de fertilizantes em doses adequadas representa a redução dos riscos de impactos ambientais, bem como relevância econômica, uma vez que contribui para a diminuição nos custos de produção pelo uso racional da quantidade aplicada de fertilizantes (NELL et al., 1997; HAVER \& SCHUCH, 1996).

A condutividade elétrica (CE) é a medida da passagem da corrente elétrica entre eletrodos submetidos a uma solução composta por solutos iônicos (cátions e ânios). Portanto, quanto maior a quantidade de fertilizantes aplicados ao solo/substrato, maior será o valor da CE.

TOMÉ JÚNIOR (1997) afirma que o excesso de sais na zona radicular, independentemente dos íons presentes, prejudica a germinação, o desenvolvimento e a produtividade das plantas. Isso ocorre porque maior concentração da solução no solo ou substrato exige da planta maior dispêndio de energia para conseguir absorver água (efeito osmótico), prejudicando seus processos metabólicos essenciais.

FARIAS (2003), estudando níveis de tensão de água em duas variedades de crisântemo de vaso (aplicação de fertilizantes simultânea à de água), encontrou valores de CE entre 0,7 e $1,2 \mathrm{dS} \mathrm{m}^{-1}$ no início do ciclo, e entre 0,5 e $1,2 \mathrm{dS} \mathrm{m}^{-1}$, no final do ciclo, para as cultivares Puritan e Rage, pela metodologia 1:2. Os maiores valores de área foliar obtidos foram em torno de $2.500 \mathrm{~cm}^{2}$. Quanto à matéria seca, o maior acúmulo foi de aproximadamente $30 \mathrm{~g}^{\text {vaso }}{ }^{-1}$ para a cultivar Puritan, e $45 \mathrm{~g}$ vaso $^{-1}$ para a cultivar Rage.

No manejo da fertirrigação em cultivo de flores em vasos, boa parte dos produtores segue padrões de adubação previamente estabelecidos, o que muitas vezes leva a produzir plantas sem padrão de qualidade, que se altera segundo as condições ambientais. Outros produtores mais tecnificados utilizam a medida da CE como referência para aumentar ou diminuir a concentração de sais na solução aplicada. De acordo com CAVINS et al. (2000), as faixas consideradas adequadas para crisântemo são 2,0 a $3,0 \mathrm{dS} \mathrm{m}^{-1}$, pelo método do extrato de saturação, e 2,6 a $4,6 \mathrm{dS} \mathrm{m}^{-1}$ pelo método "Pourthru". No entanto, faltam na literatura trabalhos que ajudem a identificar a CE mais adequada para o melhor desenvolvimento de plantas de crisântemo cultivadas em vaso.

O presente trabalho foi desenvolvido com o objetivo de avaliar os efeitos de diferentes níveis de condutividade elétrica no substrato como meio de indicar a melhor concentração de sais a ser aplicada às plantas de crisântemo cultivadas em vaso sob cultivo protegido. 


\section{MATERIAL E MÉTODOS}

O experimento foi conduzido em ambiente protegido na propriedade Steltenpool, situada no distrito de Holambra II, município de Paranapanema - SP, localizada nas seguintes coordenadas geográficas: latitude $23^{\circ} 4^{\prime} \mathrm{S}$, longitude $49^{\circ} \mathrm{W}$ e altitude de $630 \mathrm{~m}$.

Foi cultivado crisântemo (Dendranthema grandiflora Tzvelev.), variedade White Diamond, de cor branca. O substrato consistiu em mistura de $30 \%$ de terra de subsuperfície e $70 \%$ de casca de pínus fina. Conduziu-se o experimento em vasos plástico número 15 , com volume de $1,3 \mathrm{~L}$, e cada vaso continha cinco mudas com quantidade de adubos utilizados por tratamento e por fase (Tabela 1). Todas as plantas foram oriundas de um único lote de mesma idade. As estacas foram enraizadas com fitorregulador.

TABELA 1. Quantidade de adubos utilizados por tratamento na fase vegetativa e de botão no preparo de 100 L de solução, para aplicação na cultura do crisântemo.

\begin{tabular}{lrrrrr}
\hline \multirow{2}{*}{ Adubo } & \multicolumn{5}{c}{ Tratamentos } \\
\cline { 2 - 6 } & 1 & 2 & 3 & 4 & 5 \\
\hline Fase vegetativa & & & & & \\
Nitrato de Cálcio (g) & 60,00 & 70,00 & 80,00 & 90,00 & 100,00 \\
Nitrato de Potássio (g) & 18,75 & 21,88 & 25,00 & 28,13 & 31,25 \\
Sulfato de Amônio (g) & 9,38 & 10,94 & 12,50 & 14,03 & 15,63 \\
Sulfato de Magnésio (g) & 7,88 & 9,19 & 10,50 & 11,81 & 13,13 \\
MAP (g) & 19,50 & 22,75 & 26,00 & 29,25 & 32,50 \\
Tenso Ferro (g) & 4,88 & 5,69 & 6,50 & 7,31 & 8,13 \\
Starter (mL) & 4,88 & 5,69 & 6,50 & 7,31 & 8,13 \\
Molibdato de sódio (mL) & 4,88 & 5,69 & 6,50 & 7,31 & 8,13 \\
Fase de botão & & & & & \\
Nitrato de Potássio (g) & 99,38 & 115,94 & 132,50 & 149,50 & 165,63 \\
Sulfato de Magnésio (g) & 30,75 & 35,88 & 41,00 & 46,13 & 51,25 \\
MAP (g) & 9,38 & 10,94 & 12,50 & 14,03 & 15,63 \\
Nutrimins Ferro (mL) & 9,00 & 10,50 & 12,00 & 13,50 & 15,00 \\
Starter (mL) & 4,88 & 5,69 & 6,50 & 7,31 & 8,13 \\
Molibdato de sódio (mL) & 4,88 & 5,69 & 6,50 & 7,31 & 8,13 \\
\hline
\end{tabular}

Aos 26 dias após o enraizamento - (DAE), as plantas iniciaram a fase de botão, aumentando a demanda por nutrientes, havendo a necessidade de reformulação nas quantidades de nutrientes fornecidos, principalmente os mais importantes para essa fase.

Usou-se o delineamento experimental de blocos casualizados, com quatro repetições e parcelas divididas. As parcelas foram constituídas pelas épocas de amostragem, e as subparcelas, pelos diferentes níveis de condutividade elétrica, sendo cada subparcela constituída por dois vasos. Os níveis de condutividade elétrica determinados na solução aplicada foram: 1,42;1,65;1,89;2,13 e $2,36 \mathrm{dS} \mathrm{m} \mathrm{m}^{-1}$ para a fase vegetativa, e 1,$71 ; 1,97 ; 2,28 ; 2,57$ e $2,85 \mathrm{dS} \mathrm{m}^{-1}$ para a fase de botão (tratamentos T1, T2, T3, T4 e T5, respectivamente). A quantidade de vasos da área útil do experimento foi de 240 unidades, e outros 160 vasos constituíram a bordadura, distribuídos em área total de $1,70 \mathrm{~m} \times 22 \mathrm{~m}$.

Semanalmente, foram avaliadas as seguintes características de crescimento das plantas: altura de plantas (a partir da base superior do vaso até o ponto extremo encontrado na planta) e diâmetro do buquê. A cada 14 dias, foram determinadas: área foliar, cuja medição foi feita com o uso de medidor de área foliar eletrônico da marca Li-Cor, modelo L1-3100, e fitomassa seca da parte aérea, obtida após a coleta da parte aérea da planta, lavagem e secagem em estufa dotada de sistema de circulação e renovação de ar, à temperatura de $60{ }^{\circ} \mathrm{C}$, até obtenção de massa constante, sendo o material pesado posteriormente em balança digital de precisão de $0,01 \mathrm{~g}$. 
Realizou-se, aos 56 DAE, a classificação dos vasos quanto à qualidade das plantas, de acordo com o padrão exigido pelo mercado, sendo adotados os padrões estabelecidos pelo Instituto Brasileiro de Floricultura (IBRAFLOR, 2000), como também o aspecto visual de oito plantas por tratamento, às quais foram atribuídas notas.

Após 14 dias de permanência das mudas em estufa de enraizamento, essas foram transferidas para uma estufa comercial, já tendo sido submetidas ao "pinching" (poda do meristema apical para estimular o surgimento das brotações laterais, dando melhor formação às plantas). Considerou-se o início do experimento em 22-1-2004, data em que as plantas foram retiradas da estufa de enraizamento. A fase do experimento na estufa encerrou-se aos 56 DAE.

$\mathrm{O}$ experimento foi conduzido com o controle do fotoperíodo adequado à cultura do crisântemo para indução floral, e os vasos, mantidos livres de plantas daninhas. O controle fitossanitário preventivo foi feito à base de produtos regularmente utilizados na propriedade, além de ter sido aplicado regulador de crescimento. Procedeu-se à desbrota dos botões laterais aos 35 DAE, mantendo-se uma inflorescência por haste.

Utilizou-se de sistema de irrigação por gotejamento com um gotejador tipo flecha por vaso, com vazão de 4,3 $\mathrm{L} \mathrm{h}^{-1}$, na pressão de serviço de $10 \mathrm{MPa}$, sendo o regime de aplicação de água adotado de $-4 \mathrm{kPa}$ (FARIAS, 2003). A lâmina de irrigação correspondeu à quantidade de água requerida para elevar a umidade do substrato contido no vaso, ao valor correspondente à condição de máxima retenção. Para o monitoramento da irrigação, foram instalados quatro tensiômetros com manômetro de mercúrio por tratamento, na profundidade de $9,5 \mathrm{~cm}$.

Para a fertirrigação, prepararam-se cinco diferentes soluções em diferentes recipientes, de modo que cada vaso recebeu as quantidades preestabelecidas de nutrientes em um mesmo volume. Para cada tratamento, havia uma linha de irrigação, e a suspensão da fertirrigação deu-se aos 46 DAE, de acordo com SARZI et al. (2005).

A fim de avaliar e caracterizar o ambiente, foram realizados registros de temperatura do ar às $9 \mathrm{~h}$ e $15 \mathrm{~h}$, máxima e mínima, e umidade relativa do ar às $9 \mathrm{~h}$ e $15 \mathrm{~h}$, ao longo do ciclo da cultura no interior do ambiente protegido, utilizando-se de medidor de temperatura de máxima e de mínima do ar, do tipo portátil, e um higrômetro de estufa.

Os efeitos dos níveis de condutividade elétrica foram submetidos à análise de regressão em que foram testados os modelos linear e quadrático. Quando houve resposta significativa para análise de regressão, utilizou-se da equação de regressão que melhor se ajustou aos dados, escolhidas com base na significância dos coeficientes de regressão a $1 \%(* *)$ e $5 \%$ (*) de probabilidade, pelo teste $\mathrm{F}$, e no maior valor do coeficiente de determinação $\left(\mathrm{R}^{2}\right)$. Utilizou-se do teste não-paramétrico de Friedman para a análise das notas atribuídas ao aspecto visual das plantas de crisântemo, no momento final do experimento.

\section{RESULTADOS E DISCUSSÃO}

A partir dos dados observados diariamente de temperatura do ar às $9 \mathrm{~h}$ e $15 \mathrm{~h}$, os valores de temperatura máxima e mínima no interior do ambiente protegido alcançaram valores médios de máxima e de mínima de 33,4 e $21,3{ }^{\circ} \mathrm{C}$, respectivamente. A média das observações de temperatura do ar foi de $25,1^{\circ} \mathrm{C}$ às $9 \mathrm{~h}$ e de $29,6^{\circ} \mathrm{C}$ às $15 \mathrm{~h}$. A umidade relativa média do ar foi de 59,7 às $9 \mathrm{~h} \mathrm{e}$ $47,5 \%$ às $15 \mathrm{~h}$, no interior do ambiente protegido.

A análise de variância revelou efeito significativo $(\mathrm{P}<0,05)$ dos níveis de condutividade elétrica (tratamentos) sobre altura das plantas somente aos 21 DAE (Tabela 2).

O comportamento observado na altura das plantas, nas demais idades, mostra que a faixa de variação dos níveis de condutividade elétrica aplicados ao longo do tempo não afetou essa característica. Esse fato pode estar relacionado ao uso do regulador de crescimento ao longo do ciclo da planta, a partir dos 25 DAE. Deve-se considerar que, se não houvesse a aplicação de regulador de crescimento (prática usual entre os produtores de crisântemo devido ao padrão de 
altura que as plantas devem apresentar no momento da comercialização), possivelmente as diferenças entre as alturas das plantas dos diferentes tratamentos seriam significativas.

TABELA 2. Altura das plantas de crisântemo (cm) em função dos tratamentos e da idade.

\begin{tabular}{|c|c|c|c|c|c|c|c|c|c|c|}
\hline \multirow{2}{*}{$\begin{array}{c}\mathrm{CE} \\
\text { solução } \\
\left(\mathrm{dS} \mathrm{m}^{-1}\right)\end{array}$} & \multicolumn{3}{|c|}{ DAE } & \multirow{2}{*}{\multicolumn{2}{|c|}{$\begin{array}{c}\mathrm{CE} \\
\text { solução } \\
\left.(\mathrm{dS} \mathrm{m})^{-1}\right)\end{array}$}} & \multicolumn{5}{|c|}{ DAE } \\
\hline & 7 & 14 & 21 & & & 28 & 35 & 42 & 49 & 56 \\
\hline $\begin{array}{c}\text { Fase } \\
\text { vegetativa }\end{array}$ & & $\mathrm{cr}$ & & \multicolumn{2}{|c|}{$\begin{array}{c}\text { Fase de } \\
\text { botão }\end{array}$} & & & & & \\
\hline T1 1,42 & 7,9 & 10,3 & 13,6 & $\mathrm{~T} 1$ & 1,71 & 18,9 & 22,6 & 24,3 & 25,8 & 26,1 \\
\hline $\mathrm{T} 2 \quad 1,65$ & 7,8 & 11,1 & 14,6 & $\mathrm{~T} 2$ & 1,97 & 20,5 & 23,8 & 24,6 & 26,6 & 27,4 \\
\hline T3 1,89 & 7,0 & 10,4 & 14,3 & $\mathrm{~T} 3$ & 2,28 & 20,1 & 23,8 & 25,1 & 27,0 & 27,6 \\
\hline $\mathrm{T} 4 \quad 2,13$ & 7,9 & 11,2 & 14,9 & $\mathrm{~T} 4$ & 2,57 & 20,4 & 24,0 & 24,9 & 26,5 & 27,5 \\
\hline T5 2,36 & 8,5 & 11,8 & 14,9 & T5 & 2,85 & 21,1 & 24,8 & 25,3 & 26,8 & 27,8 \\
\hline $\mathrm{F}$ & NS & $\mathrm{NS}$ & $*$ & & & $\mathrm{NS}$ & NS & NS & $\mathrm{NS}$ & NS \\
\hline $\mathrm{R}^{2}$ & 0,75 & 0,62 & 0,72 & & & 0,68 & 0,84 & & & 0,65 \\
\hline
\end{tabular}

NS: não-significativo a $5 \%$ de probabilidade.

L e Q: efeitos significativos lineares e quadráticos, respectivamente.

*: significância a $5 \%$ de probabilidade.

Regressão:

7 DAE: $y=4,0622 x^{2}-14,806 x+20,84$

14 DAE: $y=1,3088 x+8,4864$

21 DAE: $y=1,2262 x+12,142$

28 DAE: $y=1,4688 x+16,857$

35 DAE: $y=1,5809 x+20,202$

42 DAE: NS

49 DAE: NS

56 DAE: $\mathrm{y}=1,1996 \mathrm{x}+24,55$

PEREIRA (2002), estudando o efeito de quatro níveis de reposição de água e três épocas de suspensão da fertirrigação, na cultura do crisântemo, variedade White Diamond, encontrou valores de altura de hastes entre 27,07 e 30,57 cm. De acordo com o Instituto Brasileiro de Floricultura (IBRAFLOR, 2000), a altura das plantas deve variar entre 23 e $35 \mathrm{~cm}$. Para STRINGHETA (1995), a altura ideal para as plantas de crisântemo em vaso deve ser entre 20 e $25 \mathrm{~cm}$. Apesar de, no experimento, terem ocorrido médias superiores a essa faixa, a homogeneidade de tamanho entre tratamentos manteve-se constante.

Houve efeito linear significativo $(\mathrm{P}<0,01)$ em todas as épocas amostradas em relação aos valores de diâmetro do buquê do crisântemo, cultivado sob diferentes níveis de condutividade elétrica (Tabela 3).

TABELA 3. Diâmetro do buquê de plantas de crisântemo $(\mathrm{cm})$ em função dos tratamentos e da idade.

\begin{tabular}{|c|c|c|c|c|c|}
\hline & \multirow{2}{*}{$\begin{array}{l}\text { CE solução } \\
\left.(\mathrm{dS} \mathrm{m})^{-1}\right)\end{array}$} & \multicolumn{4}{|c|}{ DAE } \\
\hline & & 35 & 42 & 49 & 56 \\
\hline$\overline{\text { Fase de botão }}$ & & 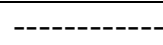 & -----. & ---- & 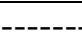 \\
\hline T1 & 1,71 & 29,9 & 30,9 & 32,3 & 37,0 \\
\hline $\mathrm{T} 2$ & 1,97 & 31,1 & 33,1 & 35,5 & 39,6 \\
\hline T3 & 2,28 & 32,4 & 34,6 & 35,4 & 38,5 \\
\hline $\mathrm{T} 4$ & 2,57 & 32,8 & 33,1 & 35,9 & 39,3 \\
\hline T5 & 2,85 & 34,1 & 36,4 & 37,8 & 42,6 \\
\hline $\mathrm{F}$ & & ** & $* *$ & $*$ & $* *$ \\
\hline$\underline{\mathrm{R}^{2}}$ & & 0,98 & 0,72 & 0,81 & 0,69 \\
\hline
\end{tabular}

Regressão $\mathrm{y}=3,50 \mathrm{x}+24,09^{*}$ $\mathrm{y}=3,79 \mathrm{x}+24,99 * *$

L: efeito significativo linear.

* e **: significância a 5 e $1 \%$ de probabilidade, respectivamente.

Quanto ao diâmetro do buquê, observou-se que, para níveis mais baixos de CE, as hastes laterais não atingiram a mesma altura que as demais, o que fez com que o buquê apresentasse 
menor diâmetro. Possivelmente, esse efeito foi devido às quantidades de nutrientes nos tratamentos com menores $\mathrm{CE}$ não atenderem integralmente à demanda de nutrientes.

A análise de variância revelou efeito significativo dos níveis de condutividade elétrica sobre os resultados de área foliar para todas as épocas amostradas (Tabela 4).

TABELA 4. Área foliar da planta de crisântemo $\left(\mathrm{cm}^{2}\right)$ em função dos tratamentos e da idade.

\begin{tabular}{|c|c|c|c|c|c|c|}
\hline \multirow{2}{*}{\multicolumn{2}{|c|}{$\begin{array}{l}\text { CE solução } \\
\left.(\mathrm{dS} \mathrm{m})^{-1}\right)\end{array}$}} & DAE & \multirow{2}{*}{$\begin{array}{l}\text { CE solução } \\
\left.(\mathrm{dS} \mathrm{m})^{-1}\right)\end{array}$} & \multicolumn{3}{|c|}{ DAE } \\
\hline & & 14 & & 28 & 42 & 56 \\
\hline \multicolumn{2}{|c|}{$\begin{array}{c}\text { Fase } \\
\text { vegetativa }\end{array}$} & $------\mathrm{cm}^{2}------$ & $\begin{array}{l}\text { Fase de } \\
\text { botão }\end{array}$ & & $--\mathrm{cm}^{2}-$ & \\
\hline $\mathrm{T} 1$ & 1,42 & 1.452 & $\mathrm{~T} 1 \quad 1,71$ & 2.021 & 2.462 & 2.404 \\
\hline $\mathrm{T} 2$ & 1,65 & 972 & $\mathrm{~T} 2 \quad 1,97$ & 2.819 & 2.915 & 2.927 \\
\hline $\mathrm{T} 3$ & 1,89 & 898 & T3 2,28 & 2.620 & 2.794 & 2.806 \\
\hline $\mathrm{T} 4$ & 2,13 & 1.038 & $\mathrm{~T} 4 \quad 2,57$ & 2.769 & 3.232 & 3.361 \\
\hline $\mathrm{T} 5$ & 2,36 & 983 & T5 2,85 & 2.769 & 3.209 & 3.037 \\
\hline $\mathrm{F}$ & & NS & & $* *$ & $* *$ & $* *$ \\
\hline $\mathrm{R}^{2}$ & & 0,81 & & 0,69 & 0,80 & 0,73 \\
\hline
\end{tabular}

NS: não-significativo a 5\% de probabilidade.

L e Q: efeitos significativos lineares e quadráticos, respectivamente.

* e **: significância a 5 e $1 \%$ de probabilidade, respectivamente.

14 DAE: $\mathrm{y}=1.384,2 \mathrm{x}^{2}-5.599,3 \mathrm{x}+6.553,1^{*}$

28 DAE: $y=-1.079,12 \mathrm{x}^{2}+5.409,2 \mathrm{x}-3.942^{*}$

42 DAE: $\mathrm{y}=624 \mathrm{x}+1.503,1 * *$

56 DAE: $\mathrm{y}=-891,1 \mathrm{x}^{2}+4.646,9 \mathrm{x}-2.905,2 *$

Observa-se que, aos $14 \mathrm{DAE}$, a área foliar foi maior para a CE de 1,42 $\mathrm{dS} \mathrm{m}^{-1}$, o que significa dizer que o menor índice salino favoreceu o desenvolvimento foliar inicial. Considerandose que nesse momento a demanda por nutrientes é ainda pequena, doses mais elevadas de sais aumentam os valores da CE na solução do substrato, possivelmente, para um nível acima do limiar, onde há gasto de energia para a absorção de água e nutrientes (LIMA, 1997). Deve-se considerar que, para a maioria das plantas na fase inicial de desenvolvimento, esse limiar é mais baixo.

À medida que a planta se desenvolveu, demandou maior quantidade de nutrientes, sendo a maior área foliar aos 28 DAE obtida com a CE de $2,51 \mathrm{dS} \mathrm{m}^{-1}$ e aos 42 e 56 DAE, para $2,57 \mathrm{dS} \mathrm{m}^{-1}$. Valores acima diminuíram a área foliar porque, de acordo com RAVIV \& BLOM (2001), as plantas reagem ao aumento da CE na solução com a redução da área foliar.

Para os valores de fitomassa seca da parte aérea da planta de crisântemo, verificou-se que os níveis de condutividade elétrica não influenciaram significativamente na sua produção (Tabela 5).

A fitomassa seca determinada aos 14; 28 e 56 DAE indica que as diferenças não foram significativas, tendo sido somente aos 42 DAE, uma vez que, no período dos 28 aos 42 DAE, houve o maior desenvolvimento da planta.

Deve-se considerar que aos 35 DAE foi realizada a desbrota de botões laterais (prática usual no cultivo dessa variedade), cuja fitomassa fresca média retirada foi de $38 \mathrm{~g} \mathrm{vaso}^{-1}$.

Considerando-se o tratamento que recebeu a $\mathrm{CE}$ de $2,57 \mathrm{dS} \mathrm{\textrm {m } ^ { - 1 }}$, verificou-se que esse proporcionou a maior fitomassa seca $\left(24,26 \mathrm{~g} \mathrm{planta}^{-1}\right)$. Valores acima diminuíram a fitomassa, possivelmente em função do desvio de energia do crescimento para adaptação ao estresse, isto é, a redução da fitomassa seca pode refletir o custo metabólico de energia, associado à adaptação à salinidade e à redução no ganho de carbono (RICHARDSON \& McCREE, 1985). Nesse aspecto, pode-se incluir a regulação do transporte e a distribuição iônica em vários órgãos e dentro das células, a síntese de solutos orgânicos para a osmorregulação e/ou proteção de macromoléculas e a manutenção da integridade das membranas. Assim, a menor redução no crescimento do genótipo tolerante pode estar associada, entre outros fatores, ao menor custo de energia para a 
osmorregulação, o qual pode ser conseguido por meio de acumulação e da compartimentação de solutos inorgânicos no vacúolo e solutos orgânicos no citoplasma (TAL, 1985).

LIMA \& HAAG (1989) encontraram peso médio semelhante de plantas de crisântemo desenvolvidas em condição de casa de vegetação e solução nutritiva.

TABELA 5. Fitomassa seca da parte aérea da planta de crisântemo $\left(\mathrm{g}\right.$ planta $\left.^{-1}\right)$ em função dos tratamentos e da idade.

\begin{tabular}{|c|c|c|c|c|c|c|c|}
\hline \multirow{2}{*}{\multicolumn{2}{|c|}{$\begin{array}{l}\text { CE solução } \\
\left(\mathrm{dS} \mathrm{m}^{-1}\right)\end{array}$}} & DAE & \multirow{2}{*}{\multicolumn{2}{|c|}{$\begin{array}{c}\text { CE solução } \\
\left(\mathrm{dS} \mathrm{m}^{-1}\right)\end{array}$}} & \multicolumn{3}{|c|}{ DAE } \\
\hline & & 14 & & & 28 & 42 & 56 \\
\hline \multicolumn{2}{|c|}{ Fase vegetativa } & --g planta ${ }^{-1}--$ & Fas & botão & \multicolumn{3}{|c|}{----------------- g planta ${ }^{-1}$--------------- } \\
\hline T1 & 1,42 & 3,86 & T1 & 1,71 & 11,42 & 20,34 & 30,73 \\
\hline $\mathrm{T} 2$ & 1,65 & 3,76 & $\mathrm{~T} 2$ & 1,97 & 14,48 & 21,68 & 32,47 \\
\hline $\mathrm{T} 3$ & 1,89 & 3,61 & $\mathrm{~T} 3$ & 2,28 & 13,54 & 22,11 & 30,45 \\
\hline $\mathrm{T} 4$ & 2,13 & 3,88 & $\mathrm{~T} 4$ & 2,57 & 12,93 & 24,26 & 33,13 \\
\hline T5 & 2,36 & 3,93 & T5 & 2,85 & 14,25 & 23,87 & 30,23 \\
\hline $\mathrm{F}$ & & NS & & & NS & NS & NS \\
\hline $\mathrm{R}^{2}$ & & & & & & 0,89 & \\
\hline Regre & & NS & & & NS & $y=3,3446 x+14,84$ & NS \\
\hline
\end{tabular}

NS: não-significativo a 5\% de probabilidade.

L: efeitos significativos lineares e quadráticos, respectivamente.

**: significância a $1 \%$ de probabilidade.

Na Tabela 6, são apresentadas as notas atribuídas ao aspecto visual dos vasos em função dos níveis de CE. Pelo teste de Friedman, há diferença significativa entre os tratamentos $(\mathrm{P}<0,05)$. Vale ressaltar que, quanto menor o somatório das notas atribuídas, melhor o resultado em análise. Contudo, o tratamento 4 foi o que proporcionou vasos com o melhor aspecto visual.

TABELA 6. Somatório das notas atribuídas ao aspecto visual dos vasos em função dos níveis de CE.

\begin{tabular}{ccc}
\hline Tratamento & CE solução $\left(\mathrm{dS} \mathrm{m}^{-1}\right)$ & Somatório das Notas \\
\hline T1 & 1,71 & $30 \mathrm{c}$ \\
T2 & 1,97 & $18 \mathrm{abc}$ \\
T3 & 2,28 & $24 \mathrm{bc}$ \\
T4 & 2,57 & $8 \mathrm{a}$ \\
T5 & 2,85 & $10 \mathrm{ab}$ \\
\hline
\end{tabular}

Médias seguidas pela mesma letra não diferem significativamente, pelo teste de comparações múltiplas de Friedman.

Os vasos foram classificados segundo os padrões estabelecidos pelo IBRAFLOR (2000). Todos os 40 vasos analisados encontravam-se dentro dos padrões de qualidade A1: plantas isentas de pragas, doenças e seus danos, com coloração verde e brilho, livre de manchas e lesões, tolerando-se a presença leve de resíduos químicos. As flores devem apresentar-se com coloração firme, livres de manchas e com florescimento uniforme e a altura das plantas deve variar entre 23 e $35 \mathrm{~cm}$. Essa classificação determina a comercialização do vaso, e não sendo o vaso de qualidade, poderá ser descartado. $\mathrm{O}$ preço dependerá dessa qualidade.

\section{CONCLUSÕES}

A condutividade elétrica demonstrou ser um parâmetro adequado para o controle de fertirrigação na cultura do criântemo cultivado em vaso. $\mathrm{O}$ tratamento correspondente à aplicação de solução com condutividade elétrica de $2,13 \mathrm{dS} \mathrm{m}^{-1}$ na fase vegetativa e $2,57 \mathrm{dS} \mathrm{m}^{-1}$ na fase de botão proporcionou o melhor aspecto visual das plantas de crisântemo cultivadas em vaso, além de apresentar o maior valor de fitomassa seca da parte aérea, a maior área foliar e a melhor formação e coloração. 


\section{REFERÊNCIAS}

CAVINS, T.J.; FONTENO, W.C.; HARDEN, B.; McCALL, I.; GIBSON, J.L. Monitoring and managing $\mathrm{pH}$ and EC using the PuorThru extraction method. Raleigh: Horticulture Information, 2000. 17 p.

FARIAS, M.F. Manejo da irrigação na cultura do crisântemo (Dendranthema grandiflora) cultivado em vaso, em ambiente protegido. 2003. 83 f. Dissertação (Mestrado em Irrigação e Drenagem) - Faculdade de Ciências Agronômicas, Universidade Estadual Paulista, Botucatu, 2003.

FARIAS, M.F.; SAAD, J.C.C. Crescimento e qualidade de crisântemo cultivado em vaso sob ambiente protegido. Horticultura Brasileira, Brasília, v.23, n.3, p.740-2, jul-set 2005.

HAVER, D.L.; SCHUCH, U.K. Production and postproductiom peformance of two new guinea impatiens cultivars grown with controlled-release fertilizer and no leaching. Journal of the American Society of Horticultural Science, Alexandria, v.121, n.5, p.820-5, 1996.

IBRAFLOR. INSTITUTO BRASILEIRO DE FLORICULTURA. Padrão Ibraflor de qualidade. Campinas: Ibraflor, 2000. 87 p.

JUNQUEIRA, A.H.; PEETZ, M.S. Crisântemos hoje e sempre: tecnologia de produção. Jaguariúna: HFF \& Citrus, 2004. p.25-7.

KIYUNA, I.; FRANCISCO, V.L.F.S.; COELHO, P.J.; CASER, D.V.; ASSUMPÇÃO, R.; ÂNGELO, J.A. Floricultura brasileira no início do século XXI: o perfil do produtor. Informações Econômicas, São Paulo, v.34, n.4, p.14-32, abr.2004.

LIMA, A.M.P.L.; HAAG, P. Absorção de macronutrientes pelo crisântemo (Chrysanthemum morfolium) cultivar Golden Polaris. In: HAAG, H.P.; MINAMI, K; LIMA, A.M.L.P. Nutrição de algumas espécies ornamentais. Campinas: Fundação Cargill, 1989. p.64-102.

LIMA, L.A. Efeitos de sais no solo e na planta. In: GHEYI, H.R.; QUEIROZ, J.E.; MEDEIROS, J.M. (Ed.). Manejo e controle da salinidade na agricultura irrigada. Campina Grande: UFPB/ SBEA, 1997. p.113-36.

NELL, T.A.; BARRETT, J.E.; LEONARD, R.T. Production factors affecting postproduction quality of flowering potted plants. Hortscience, Alexandria, v.32, n.5, p.817-19, 1997.

PEREIRA, J.R.D. Análise dos efeitos da época de suspensão da fertirrigação e de níveis de reposição de água à cultura do crisântemo (Dendranthema grandiflora) cv. White diamond. 2002. 54 f. Dissertação (Mestrado em Irrigação e Drenagem) - Universidade Federal de Lavras, Lavras, 2002.

RAVIV, M.; BLOM, T.J. The effect of water avaliability and quality on photosynthesis and productivity of soilless - grow cut roses. Scientia Horticulturae, Amsterdam, v.88, n.3, p.257-76, 2001.

RICHARDSON, N.S.G.; MCCREE, K.J. Carbon balance and water relations of sorghum exposed to salt and water stress. Plant Physiology, Rockville, v.79, n.4, p.1015-20, 1985.

SARZI, I.; MOTA, P.R.D’A.; VILLAS BÔAS, R.L. Características químicas e longevidade de plantas envasadas de crisântemo em função da adubação final. Científica, Jaboticabal, v.33, n.1, p.57-61, 2005.

STRINGETA, A.C.O. Avaliação de variedades de crisântemo em vaso, em substratos contendo composto de lixo urbano. 1995. 72 f. Dissertação (Mestrado em Fitotecnia) - Universidade Federal de Viçosa, Viçosa - MG, 1995.

TAL, M. Genetics of salt tolerance in higher plants: theoretical and practical considerations. Plant and Soil, Dordrecht, v.89, n.2, p.199-226, 1985.

TOMÉ JÚNIOR, J.B. Manual para interpretação de análise de solo. Curitiba: Editora Guaíba Agropecuária, 1997. 247 p. 